\title{
Implications of a Changing Economic Structure for the Strategy of Monetary Policy
}

\author{
Carl E. Walsh*
}

February 25, 2004

\begin{abstract}
This paper surveys the implications of uncertainty for the design of monetary policy. Among the topics discussed are the impact of imperfect or noisy information on the performance of simple rules, the performance of rules that are robust to the exogenous disturbance processes, the effects of parameter uncertainty, and the implications of robust control. The analysis is conducted using a new Keynesian framework. One finding is that difference rules seem to perform well in the presence of imperfect information about the output gap.
\end{abstract}

\section{Introduction}

Much of the recent research on monetary policy reflects a consensus outlined by Lars Svensson at the 1999 Jackson Hole Conference (Svensson 1999). This consensus is based on the view that

\footnotetext{
*Professor, University of California, Santa Cruz and Visiting Scholar, Federal Reserve Bank of San Francisco (walshc@ucsc.edu). This paper was prepared for the Federal Reserve Bank of Kansas City's Jackson Hole Conference, Aug. 29-30, 2003. I would like to thank my discussant David Longworth, conference participants, and Federico Ravenna, Glenn Rudesbusch, and John Williams for helpful comments and discussions. Any opinions expressed are not necessarily those of the Federal Reseve Bank of San Francisco or the Federal Reserve System.
} 
central banks should minimize inflation volatility and the volatility of the gap between output and the flexible-price equilibrium level of output. Less consensus exists on the best strategies for achieving these goals. While Svensson emphasized the role of optimal policies, research has also focused on simple instrument rules of the type first popularized by John Taylor (1993). Inflation forecast targeting, general targeting rules, nominal income growth, price level targeting, and exchange rate targeting are just some of the other policy strategies that have been analyzed. However, much of this work ignores issues of structural change and uncertainty. The central bank is assumed to know the true model of the economy and observe accurately all relevant variables. The sources and properties of economic disturbance are also taken to be known. Uncertainty arises only due to the unknown future realizations of these disturbances.

In practice, policy choices are made in the face of tremendous uncertainty about the true structure of the economy, the impact policy actions have on the economy, and even about the current state of the economy. Because uncertainty is pervasive, it is important to understand how alternative policies fare when the central bank cannot accurately observe important macro variables or when it employs a model of the economy that is incorrect in unknown ways. It is particular important to search for policies that are able to deliver good macroeconomic outcomes even when structural changes are continually occurring and/or the central bank is uncertain as to the true structure of the economy.

Two traditional results are relevant for any such search. First, Poole (1970) showed how the choice of an operating procedure depends on the types of disturbances affecting the economy. The general shift over the past twenty years from strategies in which monetary aggregates played important roles to ones in which money plays little explicit role reflects the forces first systematically studied by Poole. His approach continues to be reflected in discussions of the choice between broad policy strategies such as monetary targeting, exchange rate policies, and inflation 
targeting.

Poole's analysis incorporated additive disturbances, and optimal policy in his model satisfied the principle of certainty equivalence, with the central bank responding to its best estimate of the unobserved shocks as if the shocks were observed perfectly. But as Poole's work also demonstrated, policy based on a simple instrument rule or intermediate targeting strategy would be altered by any change in the structure of disturbances affecting the economy.

A second key result that has influenced thinking on monetary policy and uncertainty is due to Brainard (1967). He showed that multiplicative uncertainty would lead policy makers to react more cautiously to economic disturbances - certainty equivalence would not hold. While Craine (1979) demonstrated that caution was not always the appropriate reaction, Brainard's general result seemed to capture the way actual policy makers viewed their decisions (Blinder 1998).

Recent research has offered some new perspectives on these traditional insights. Rules have been proposed that are robust to shifts in the structure and behavior of economic disturbances, for example, and notions of caution and aggression have been augmented by the idea that a desire for robust policies may lead policy makers to employ a deliberately distorted model of the economy. The traditional Bayesian approach to uncertainty requires that the central bank assess the joint probability distribution over all outcomes and then maximize the expected value of its objective function. But defining in any meaningful sense the probabilities of unusual, unique, or never before observed events-a zero nominal interest rate, the impact of information technologies, a prolonged occupation of Iraq, or the occurrence of an event like September 11th-is a difficult if not impossible task. The research on robust control has examined how the uncertainty presented by these types of events might affect a policy maker's decisions.

To discuss some of these new perspectives and their implications for monetary policy, and because uncertainty can take many forms, making generalizations difficult, I focus on three spe- 
cific sources of uncertainty - data uncertainty in measuring the output gap, uncertainty about the persistence of inflation shocks, and uncertainty about the inflation process itself. While representing only a small subset of the model uncertainty faced by central banks, each is among the most critical for policy design. The difficulties of estimating the output gap have created problems for policy makers in the past. Inflation shocks present policy makers with their most difficult trade-offs, and the nature and sources of these shocks is a matter of debate. Finally, the structure of the inflation process itself is critical for the design of policy, and the degree of inertia in the inflation process is a key factor that distinguishes alternative structural models used for policy analysis.

In an environment of change and uncertainty, policy making is difficult and simple guidelines for decision making are useful. To assess the form that these guidelines might take, I examine how sensitive different policies are to uncertainty. For example, while the difficulty of measuring of the output gap is a well recognized problem, I argue that rules based on growth rates or changes in the estimated gap suffer fewer measurement problems and outperform Taylor rules. I compare instrument rules that are robust with respect to the behavior of exogenous disturbances to other simple rules to assess the gain offered by robust rules, and I assess the sensitivity of simple rules to inertia in the inflation process.

An important aspect of an assessment of policy guidelines is determining how well they do if they turn out to be based on incorrect assumptions. Does a rule that was optimal continue to do reasonable well if the economic structure changes or if a disturbance thought to be transitory turns out to be more persistent? A Bayesian approach would evaluate the expected value of the policy maker's objective function under all possible outcomes. An alternative approach, admittedly more heuristic, examines whether the costs of being wrong are asymmetric. Is it more risky to underestimate the problem of data uncertainty or to overestimate it? Is it better to overestimate 
the degree of inertia in the inflation process or to underestimate it? As I discuss in sections 2 - 4, underestimating the degree of data uncertainty, the persistence of shocks, or the degree of inertia in inflation may lead to greater policy errors than the reverse. When assigning probabilities to all possible contingencies is difficult, it may be useful for policy makers deliberately to distort the model of the economy on which they base policy, attributing more inertia to inflation, for example, than the point estimates would suggest. The research on robust control shows how a desire for robustness is based ultimately on the policy maker's attitudes towards risk. A risk sensitive policy maker should adopt policies designed to perform well when inflation shocks are very persistent and inflation is highly inertial. Such policies are precautionary in nature-they help insure against the worst-case outcome.

In the remainder of this section, I touch briefly on some issues related to policy strategies and I then highlight the basic sources of model uncertainty. Sections $2-5$ deal with issues of data uncertainty associated with the output gap, robust instrument rules, parameter uncertainty, and robust control. A brief concluding section then follows.

\section{Strategies for monetary policy in the face of uncertainty and structural change}

Strategies involve "the art of devising or employing plans or stratagems toward a goal" (Merriam-Webster), and a monetary strategy provides "a systematic framework for the analysis of information and a set of procedures designed to achieve the central bank's main objectives" (Issing 2002). Thus, a monetary policy strategy has three components; objectives, an information structure, by which I mean a framework for distilling relevant information into a form useful for guiding policy makers, and an operational procedure that determines the setting of the policy instrument. Structural change and uncertainty affect each of these components.

\section{Policy goals}

Strategies that are based more closely on the ultimate objectives of policy are likely to be 
more robust to shifts in the economy's structure or to uncertainties about the transmission process linking instruments and goals. I will follow the broad consensus described by Svensson (1999) in assuming that the objectives of the central bank are to maintain a low and stable rate of inflation, to stabilize fluctuations of output around some reference level, and, although this is more controversial, to stabilize interest rate fluctuations. In practice, the reference level is a measure of de-trended output, although theory suggests it should be the output level that would occur in the absence of nominal rigidities. The relative weights a central bank should place on these objectives is not independent of the economy's structure. For example, if information technologies lower the cost of price adjustment and thereby lead to greater price flexibility, the central bank should raise the relative weight it places on output stabilization (Woodford 1999). For the most part, I will ignore the potential impact of structural change and uncertainty on the policy maker's preferences, focusing instead on the other two components of a policy strategy.

\section{Information}

Monetary policy strategies act as filters through which information is distilled. A strategy such as monetary targeting or nominal income growth targeting defines an intermediate target, with the policy instrument adjusted in light of movements in the intermediate target. As is well known, the optimal reaction to an intermediate target depends on the information about underlying disturbances contained in the target variable. The usefulness of intermediate targets that are not also ultimate policy objectives depends on the stability of the economy's structure and the predictability of the linkages between the intermediate target and the goals of policy. Policy regimes that target variables subject to large measurement errors or that are inherently difficult to observe may be less robust to shifts in the structure of the economy.

\section{Policy implementation}

A strategy also includes a procedure for implementing policy. Under the rules for good policy 
set out by Svensson (2003), a set of conditional forecast paths for the goal (target) variables should be constructed for a set of alternative instrument paths. In the face of uncertainty about the true model, these forecast paths can be constructed using several alternative models. The resulting forecasts for the target variables are then presented to the policy makers who select the instrument path yielding the most desired outcomes. When preferences over goal variables are quadratic and the transmission mechanism is linear, policy makers need to consider only mean forecasts; the uncertainty surrounding these forecast is irrelevant (certainty equivalence). When these conditions do not hold, Svensson calls for the construction of conditional probability distributions over the target variables, with policy makers then choosing from among the distributions. ${ }^{1}$

Three aspects of this procedure bear highlighting. First, there is a separation between the preparation of the forecast paths and the choice of the optimal path. One is carried out by the staff economists, the other is made by the appointed policy makers. Second, the exercise is dependent on the selection of the alternative instrument rate paths. One way this can be done is to restrict the instrument to follow a simple rule. Except in extremely simple models, these rules are not optimal, but research has suggested that simple instrument rules perform well in a variety of models. ${ }^{2}$ Third, if certainty equivalence does not apply, distributional forecasts

\footnotetext{
${ }^{1}$ See Jenkins and Longworth (2002) for a discussion of how the Bank of Canada formulations policy in the face of uncertainty.

${ }^{2}$ See, for example, Williams (2003). Levin and Williams (2003a) find that a simple Taylor rule, in which the nominal interest rate adjusts to its lagged value, inflation, and the output gap, performs well across a set of models. This leads them to conclude that

"...the members of a policymaking committee that share similar preferences for stabilizing fluctuations in inflation, output, and interest rates, but who have quite different views of the dynamic behavior of the economy, can relatively eas(ily) come to a mutually acceptable compromise over the design of monetary policy." (p. 20)
} 
require that a probability measure be defined over all possible future structural changes and economic disturbances. It may be difficult to define the probabilities associated with future shifts in productivity growth, the persistence of exogenous factors that affect the economy, or unforeseen future structural changes.

In the face of uncertainty and structural change in the economy, simple rules may still provide useful guidelines for policy. Evolutionary psychologists speak of the brain having developed "cheap tricks" for processing information (Bridgeman 2003). In the visual area, for example, these tricks allow humans to judge distance quickly. By employing simple ways of processing information in complex situations, rather than relying on more complex, possibly optimal filtering techniques, generally good results are obtained. Perhaps a simple instrument rule is the monetary policy equivalent of such a cheap trick.

\section{Summary}

Objectives, the structure of information, and the rule for implementing policy are all dependent on the policy maker's understanding of the economy's structure, the sources of economic disturbances, the quality of data, and the transmission mechanism for monetary policy. Because there is a wide consensus on objectives, and because uncertainty is likely to be most relevant for how the policy maker utilizes information and implements policy, it is these last two aspects of strategy on which I focus.

\section{Sources of uncertainty}

Central banks face many sources of uncertainty, some arising because of the continual structural changes occurring in a dynamic economy, some because of limitations in economic data, some because of the inherent unobservability of important macro variables, some because of disagreements over theoretical models. To organize a discussion of uncertainty, it is helpful to set out a simple way of classifying the differences between the true model of the economy and the 
model the central bank uses to design policy.

Suppose the true model of the economy is given by

$$
y_{t+1}=A_{1} y_{t}+A_{2} y_{t \mid t}+B i_{t}+u_{t+1}
$$

where $y_{t}$ is a vector of macroeconomic variables (the state vector), $y_{t \mid t}$ is the optimal, current estimate of this state vector, and $i_{t}$ is the policy maker's control instrument. In this specification, $u_{t+1}$ represents a vector of additive, exogenous stochastic disturbances. These disturbances are equal to $C e_{t+1}$, where the vector $e$ is a set of mutually and serially uncorrelated disturbances with unit variances. $A_{1}, A_{2}, B$, and $C$ are matrices containing the parameters of the model. This specification is restrictive but common - all recent analyses of monetary policy have been carried out in the type of linear framework represented by (1), although in most cases, the left side involves expectations of the $t+1$ variables. $^{3}$

Central banks must base their decisions on an estimated model of the economy and on estimates of the current state. Suppose the bank's estimates of the various parameter matrices are denoted $\bar{A}_{1}, \bar{A}_{2}, \bar{B}$, and $\bar{C}$, while $\bar{y}_{t \mid t}$ denotes the policy maker's estimate of the current state $y_{t}$. Then, letting $A=A_{1}+A_{2}$ and $\bar{A}=\left(\bar{A}_{1}+\bar{A}_{2}\right)$, we can write the central bank's perceived or reference model as

$$
y_{t+1}=\bar{A} \bar{y}_{t \mid t}+\bar{B} i_{t}+\bar{C} e_{t+1}
$$

while the true model then becomes

$$
y_{t+1}=\bar{A} \bar{y}_{t \mid t}+\bar{B} i_{t}+\bar{C}\left(e_{t+1}+w_{t+1}\right)
$$

\footnotetext{
${ }^{3}$ The variables in the model are typically interpreted as applying to log deviations around a steady-state. This is potentially problematic when it may be the steady state that is itself subject to structural change (see Sims 2001).
} 
where

$$
\begin{aligned}
\bar{C} w_{t+1}= & A_{1}\left(y_{t}-y_{t \mid t}\right) \\
& +\left[(A-\bar{A}) \bar{y}_{t \mid t}+(B-\bar{B}) i_{t}+(C-\bar{C}) e_{t+1}\right] \\
& +A\left(y_{t \mid t}-\bar{y}_{t \mid t}\right) .
\end{aligned}
$$

The difference between the central bank's reference model and the true model is represented by $\bar{C} w_{t+1}$. This term captures three sources of model specification error: ${ }^{4}$

1. Imperfect information: The first term in (2), $A_{1}\left(y_{t}-y_{t \mid t}\right)$, arises from errors in estimating the current state of the economy. As emphasized by Orphanides (2003b), errors in estimating important macro variable such as potential output have led to significant policy errors. $y_{t}$ and $y_{t \mid t}$ can differ because of data uncertainties associated with measurement error and because some variables in $y_{t}$ may be inherently unobservable.

2. Model mis-specification: The second bracketed set of terms in $w_{t+1}$ arises from uncertainty with respect to the parameters of the model. This term includes errors in the central bank's estimate of the parameters of the model; it also captures errors in modelling the structural impacts of exogenous disturbances. ${ }^{5}$ For example, mistakenly believing a relative transitory increase in oil prices represented a more permanent shock to the economy would be reflected in the $(A-\bar{A})$ term. Treating an oil price shock as affecting only the supply side and ignoring its demand effects would be reflected in a non-zero value of $C-\bar{C}$.

3. Asymmetric information and/or inefficient forecasting: The third term, $A\left(y_{t \mid t}-\bar{y}_{t \mid t}\right)$,

\footnotetext{
${ }^{4}$ The nature of the specification error represented by $w$ is somewhat more general than might at first appear. For example, if the central bank's model does not contain variables that are actually relevant, this would be reflected in zero elements in $\bar{A}, \bar{B}$, and $\bar{C}$ with corresponding non-zero elements in $A, B$, and $C$.

${ }^{5}$ Since the matrix $A_{1}$ contains the parameters governing the time series properties of the exogenous disturbances, incorrect estimates of their data generating process cause $\bar{A}_{1}$ to differ from $A_{1}$.
} 
reflects any inefficiencies in the central bank's estimate of the current state vector. It can also be interpreted as arising from informational asymmetries such as occur when the private sector has better information than the policy maker about current macroeconomic developments, or, conversely, when the policy maker has better information, for example, about its target for inflation.

Model uncertainty both in terms of the structural parameters and the behavior of the exogenous disturbances, imperfect information, and asymmetric information can be thought of as the underlying sources of uncertainty faced by the central bank. I will have little to say concerning the third source (asymmetric information and/or inefficient forecasting). While structural change may make forecasting more difficult, and by being more transparency the central bank can reduce confusion about its own objectives, the major concern of a central bank in an environment of change must lie with the first two sources of uncertainty.

\section{Imperfect or noisy information}

While information is plentiful (Bernanke and Boivin 2003), it is also noisy. Data limitations imperfect measurement, data lags - make it inevitable that real-time data provide only imperfect measures of current economic conditions. In addition, many of the variables that play critical roles in theoretical models cannot be observed directly. The most prominent example is the measure of real economic activity relevant for policy. Policy makers recognize that they should focus on a measure of output (or unemployment) adjusted for productivity (for the natural rate of unemployment), but how this adjustment should be done is controversial in theory and difficult in practice. Output gaps are traditionally defined with reference to an estimate of trend output, but shifts in trends are difficult to detect in a timely fashion. In new Keynesian models, the output gap depends on the level of output that would occur in the absence of any nominal price 
rigidities which, like the natural rate of unemployment is unobservable.

The importance of output gap measurement error for policy has been stressed by Orphanides (2003b). He argues that central banks overestimated trend output during the 1970s because the productivity slowdown was not immediately evident. As a result, the output gap was underestimated, leading monetary policy to be too expansionary. The 1990s saw a rise in productivity growth, and while the errors of the 1970s were not repeated, there was great uncertainty at the time surrounding estimates of trend output and the gap.

Aoki (2003) shows how imperfect information can lead the optimal policy to display reduced reaction to observed variables, reflecting the data noise inherent in the observed variables. This attenuation, however, does not reflect the cautious response that Brainard (1967) showed could arise in the presence of model uncertainty. Instead, the attenuation reflects the signal to noise ratio in the imperfect observation on macro variables. In our standard models (linear-quadratic structure, symmetric information), the optimal policy response to the best estimate of the state is unaffected by data uncertainty - certainty equivalence still applies (Pearlman 1992). ${ }^{6}$ Imperfect information does not support the conclusion that the central bank should rely less heavily on estimates of the output gap in formulating monetary policy, since optimal responses to estimates of inflation and the output gap are not reduced. However, if measured data contains noise, optimal responses to observed variables such as actual output will be attenuated relative to the full information case.

While certainty equivalence may characterize optimal policy, certainty equivalence does not hold for simple rules (Levine and Currie 1987). The optimal response coefficients in such rules depend on the variances and covariances of the structural disturbances and on the noise in the data. This makes it more difficult to draw general conclusions about how the response coefficients

\footnotetext{
${ }^{6}$ Svensson and Woodford (2002, 2003a) have explored issues raised by imperfect information in the type of forward-looking model commonly used for monetary policy analysis.
} 
in simple rules will be altered once measurement error and data uncertainty are taken into account. Using estimated backward-looking macro models, Smets (1999), Peersman and Smets (1999), and Rudebusch (2001) find that data uncertainty reduces the optimal coefficient on the output gap in a Taylor rule, while Ehrman and Smets (2002) show that the optimal weight to place on output gap stabilization declines when the gap is poorly measured.

Orphanides (2003a) has also investigated the implications of imperfect information for simple policy rules. Based on real-time data and a backward-looking model estimated on U.S. data, he finds that implementing the Taylor rule that would be optimal in the absence of data noise leads to substantially worse policy outcomes than occur when the noise is appropriately accounted for in the design of the policy rule.

One solution to data uncertainties is to alter the set of variables the policy maker reacts to. For example, in a model of inflation and unemployment, Orphanides and Williams (2002) find that including the change in the unemployment rate, rather than its level, ameliorates problems of measuring the natural rate of unemployment. Specifically, they assume a simple, modified Taylor rule of the form

$$
i_{t}=\theta_{i} i_{t-1}+\theta_{\pi} \pi_{t}+\theta_{u}\left(u_{t}-u_{t}^{n}\right)+\theta_{\Delta u}\left(u_{t}-u_{t-1}\right),
$$

where $i$ is the nominal interest rate, $\pi$ is the inflation rate, $u$ is the unemployment rate, and $u^{n}$ is the (unobserved) natural rate of unemployment. They show that as the degree of uncertainty about $u^{n}$ (measured by the variance of forecast errors) increases, the parameters in this rule converge to a first difference rule in which the coefficient on the lagged interest rate equals one and that on the unemployment gap goes to zero. That is, $\theta_{i} \rightarrow 1$, and $\theta_{u} \rightarrow 0$. In this form, the rule does not depend directly on an estimate of the natural rate of unemployment, making it more robust to data uncertainty than are rules that rely on an estimate of unemployment relative to the natural rate. 
The use of a rule based on the change in the unemployment rate solves one aspect of the imperfect information problem - it includes only variables for which measurement errors are viewed as small; it does not include variables that are poorly measured, or, as in the case of the natural rate of unemployment, variables that are unobservable. However, most policy rules incorporate an output gap, not an unemployment rate gap. Do Orphanides and William's findings on difference rules apply to instrument rules based on an output gap measure?

Real-time errors in predicting output relative to trend arise from two sources. First, the predictions depend on currently available data on GDP, which are revised over time. Second, even if completely accurate data were immediately available, trend GDP would still be difficult to estimate. For example, only as more time passes will it be possible to tell how much the technology boom of the late 1990s altered the economy's trend growth rate - our assessment of trend growth for the 1990s will be better in, say, 2010 when we can look both backward from 1990 and forward in time to the first decade of the 2000s. According to Orphanides and van Norden (2002), this second source of error, not data revisions, is the major problem in measuring the current level of trend output and therefore in measuring the output gap.

Errors in measuring the level of trend output are likely to be quite persistence. As a consequence, these errors tend to wash out when one looks at how the measured gap is changing over time. A first difference rule is likely to be less sensitive to mismeasuring the level of trend output correctly. For example, suppose

$$
x_{t}^{o}=x_{t}+\theta_{t}
$$

where $x_{t}^{o}$ is the measured gap and $\theta_{t}$ is the measurement error. Suppose $\theta_{t}=\rho_{\theta} \theta_{t-1}+v_{t}$ with $\rho_{\theta}$ close to 1 . The variance in the measurement error for the level of the gap is $\sigma_{v}^{2} /\left(1-\rho_{\theta}^{2}\right)$; the variance of the error in the measured change in the gap is $2 \sigma_{v}^{2} /\left(1+\rho_{\theta}\right)$. Thus, as long as $\rho_{\theta}>0.5$, the measurement error in the change is smaller than that in the level. Orphanides 
(2003) estimates that $\rho_{\theta} \approx 0.9$ for the U.S. over the period 1980-1992. In this case, the change measurement error variance is only one fifth as large as the level measurement error variance.

To assess the error in a typical measure of the output gap, the solid line in figure 1 shows the difference between two estimates of the level of the output gap. The first estimate is based on actual output at each date $t$ and an estimate of trend output obtained using data up to date t; the second estimate uses data from the entire sample from 1959:1 to 2003:1 to estimate trend output. ${ }^{7}$ The difference between these two estimates provides an indication of measurement error due to revisions in the estimate of trend output. The dashed line in the figure is the revision to the estimated change in the gap. As is clear, the change in the gap is subject to much smaller revisions. $^{8}$

Another means of assessing the measurement error in the level estimates and the change estimates is to examine the correlation between the initial estimate and the subsequent revision. If the initial estimate is an efficient forecast of the final figure, than the revision should be uncorrelated with the initial estimate. Regressing the revision in the level of the gap estimate on the initial estimate yields the following result:

$$
\begin{gathered}
x_{t}^{f}-x_{t}^{o}=0.001 \quad-0.476 \quad x_{t}^{o} \\
(1.32) \quad(7.07) \\
\text { S.E.E. }=0.014
\end{gathered}
$$

The relationship between the initial estimate and the revision is statistically significant and negative; almost half of any initial estimated output gap is likely to be subsequently reversed.

In contrast, the initial estimate of the change in the gap is unrelated to the final estimate of

\footnotetext{
${ }^{7}$ Thus, I ignore the problems of real time data revisions to focus on the revisions of trend estimates that Orphanides and van Norden stress are most important. Trend output is estimated using an H-P filter.

${ }^{8}$ The mean absolute revision in the level is $1.38 \%$ and the standard deviation of the revisions is $0.84 \%$; for the change in the gap, the mean absolute revision is $0.29 \%$ and the standard deviation is $0.23 \%$.
} 
the change:

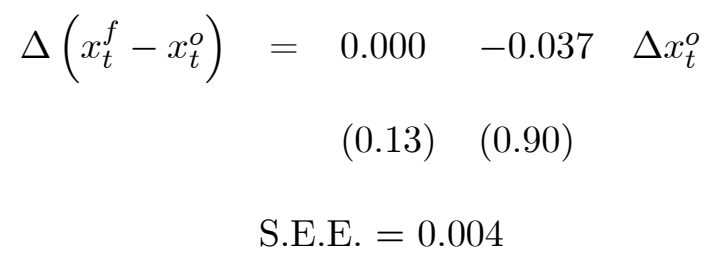

Replacing the level of the gap with the change in the output gap converts a Taylor rule into what has been described as a speed limit policy, “... where policy tries to ensure that aggregate demand grows at roughly the expected rate of increase of aggregate supply, which increase can be more easily predicted" (Gramlich 1999). Letting $y_{t}$ denote the log of output and $y^{n}$ the $\log$ of trend output, and interpreting aggregate demand to mean actual output and aggregate supply to be trend output, the growth rate of demand relative to the growth rate of supply is $\left(y_{t}-y_{t-1}\right)-\left(y_{t}^{n}-y_{t-1}^{n}\right)$. This is just equal to $x_{t}-x_{t-1}$, the change in the gap.

While the change in the gap or the growth rate of output relative to trend may ameliorate some of the measurement errors inherent in the level of the gap, it does not follow that reacting to the gap change will effectively stabilize inflation and the level of the gap. After all, it is the gap that enters the loss function, not the change in the gap. Fortunately, there is evidence that difference rules perform well in basic new Keynesian models. Walsh (2003a) finds that in a discretionary policy environment policies that stabilize inflation and the change in the output gap can outperform inflation targeting. Policies that involve nominal income growth would also face smaller measurement error problems, and Jensen (2002) shows nominal income growth targeting can improve over inflation targeting. Neither of these two papers incorporate any measurement error and so therefore understate the potential gains from gap change or nominal income growth policies. The source of the improved performance they find for nominal income growth and speed limit targeting regimes is due to the greater inertia these policies introduce. Woodford (1999) showed that inertia - or history dependence - is an important component of an optimal 
commitment policy. By focusing on output growth (as is the case under nominal income growth targeting) or the change in the gap (as in a speed limit policy), policy actions depend, in part, on output or the gap in the previous period. In fact, Mehra (2002) finds that the change in the output gap does as well as the level in a simple Taylor rule in predicting Fed behavior, and Erceg and Levin (2003) argue that the output growth rate is the appropriate output measure to include in an estimated Fed reaction function.

\section{The performance of simple rules with imperfect information}

To further assess Taylor rules and first difference rules, I examine their performance in a simple new Keynesian model. This model, or variants of it, has seen wide usage in research on monetary policy rules. The model emphasizes the importance of forward-looking expectations, and its behavior can contrast which that implied by backward-looking models in critical ways.

The benchmark new Keynesian model consists of two key structural relationships. ${ }^{9}$ The first equation relates the output gap $x_{t}$ to its expected future value and the real interest rate gap, the difference between the actual real interest rate and the natural rate $r_{t}^{n}$ :

$$
x_{t}=E_{t} x_{t+1}-\left(\frac{1}{\sigma}\right)\left(i_{t}-E_{t} \pi_{t+1}-r_{t}^{n}\right)
$$

The natural real rate of interest $r_{t}^{n}$ is equal to $\sigma\left(E_{t} y_{t+1}^{n}-y_{t}^{n}+v_{t}\right)$, where $u_{t}$ is a taste shock that affects the optimal intertemporal allocation of consumption for a given real rate of interest. I assume the natural rate of output $y^{n}$ evolves according to

$$
y_{t}^{n}=\rho_{y} y_{t-1}^{n}+\chi_{t}
$$

The second structural relationship is the inflation adjustment equation arising in the presence of sticky nominal prices:

$$
\pi_{t}=\beta E_{t} \pi_{t+1}+\kappa x_{t}+e_{t}
$$

\footnotetext{
${ }^{9}$ See Walsh (2003b, Chapter 5) for further discussion and references.
} 
The cost shock $e_{t}$ captures any factors affecting inflation that alter the relationship between real marginal costs and the output gap. Disturbances are treated as exogenous and follow $A R(1)$ processes:

$$
\begin{aligned}
& v_{t}=\rho_{v} v_{t-1}+u_{t} ; \\
& e_{t}=\rho_{e} e_{t-1}+\varepsilon_{t} .
\end{aligned}
$$

Following Woodford (2002), the central bank's objective is to minimize a loss function that depends on the variation of inflation, the output gap, and the nominal rate of interest:

$$
L_{t}=\left(\frac{1}{2}\right) E_{t} \sum_{i=0}^{\infty} \beta^{i}\left[\pi_{t+i}^{2}+\lambda_{x} x_{t+i}^{2}+\lambda_{i}\left(i_{t+i}-i^{*}\right)^{2}\right]
$$

To study the role of imperfect information, I compare the cases in which the central bank observes inflation and the output gap to one in which only noisy signals on inflation and actual output are observed. For each of these cases, I evaluate alternative rules for the case in which the natural rate of output is $i . i . d .\left(\rho_{y^{n}}=0\right)$ or highly serially correlated $\left(\rho_{y^{n}}=0.9\right)$. Gaspar and Smets (2002) find that the serially correlation properties of the cost shock are important for the costs of imperfectly observing the output gap, so I also consider the case in which $\rho_{e}=0.35$. Because the measurement error is taken to be serially uncorrelated, the error in measuring the change in the gap should be larger than that in the level of the gap. The simulations reported below, therefore, are biased against the rule based on the difference in the gap.

Calibrated values of the parameters are given in Table 1. These are taken from Giannoni and Woodford (2002b) and are based on both the empirical work of Rotemberg and Woodford (1997) and the theoretical work by Woodford (2002) in linking the weights in the objective function to the structural parameters of the model. ${ }^{10}$ I assume the variance of demand shocks reflected in

\footnotetext{
${ }^{10}$ The value of $\sigma$ implies an interest elasticity of output equal to 6.25 , much larger than typical estimated values. The value of $\kappa$, the gap elasticity of inflation is in the range of empirical estimates discussed by McCallum and Nelson (2000). The weight $\lambda_{x}$ on the output gap in the loss function is low relative to other studies which often
} 
the natural real rate of interest is twice that of cost shocks. Based on Orphanides (2003a), I set the standard deviations of the measurement error equal to 0.01 for the flexible-price output level and 0.0017 for inflation. ${ }^{11}$

Two alternative simple rules are considered. The first is a Taylor rule of the form

$$
i_{t}=\alpha_{i} i_{t-1}+\alpha_{\pi} \pi_{t}+\alpha_{x} x_{t \mid t}
$$

and is denoted by TR. The second, denoted DR, is a first difference rule:

$$
i_{t}=i_{t-1}+\alpha_{\pi} \pi_{t}+\alpha_{\Delta x}\left(x_{t \mid t}-x_{t-1 \mid t}\right) .
$$

Table 2 gives the losses under the optimal commitment policy, an optimal Taylor rule (TR), and an optimal first difference rule (DR). ${ }^{12}$ Three conclusions can be drawn. First, while outcomes deteriorate with measurement error, the effects in this purely forward-looking model are generally not large. ${ }^{13}$ Second, as found by Gaspar and Smets, serially correlation in the inflation shock compounds the problems due to measurement error. Third, the difference rule always outperforms the Taylor rule, delivering results quite close to the commitment case.

The results in Table 2 here are broadly consistent with other research that finds data unset $\lambda_{x}$ in the range 0.25 to 1 . Note that inflation is expressed at a quarterly rate; if inflation is at annual rates, the corresponding value of $\lambda_{x}$ would be 0.77 , well within the range generally employed. The weight in the interest rate term, $\lambda_{i}$, is from Woodford (2002). Woodford dervies this weight from the values of the underlying parameters of his model. Other authors typically pick values for $\lambda_{i}$ that are similar in magnitude (0.05 is common).

${ }^{11}$ Only the relative standard deviations of the various disturbances matters for the coefficients in the optimal simple rules. Orphnides (2003a) estimates the measurement error standard deviation to be 0.0093 for the output gap and as 0.0069 for inflation at annual rates (or 0.0017 at the quarterly rates employed in the theoretical specification).

${ }^{12}$ Gerali and Lippi (2002) provide a toolkit for solving for optimal discreationary and commitment policies in forward-looking models with imperfect information.

${ }^{13}$ Similarly, McCallum (2001) finds that replacing $x_{t}$ with $E_{t-1} x_{t}$ is a Taylor rule has relatively little impact of the resulting variances of inflation or the output gap unless the central bank reacts very strongly $\left(\alpha_{x}=50.0\right)$ to the estimated output gap. 
certainty has only modest implications for optimal simple rules. ${ }^{14}$ Thus, data uncertainties and mismeasurements may not be the most critical uncertainty related to the output gap. Instead, as McCallum (2001) argues, disagreement over the proper definition of the gap is likely to be more important, with theoretical models interpreting the gap as the difference between actual output and the level of output that would occur in the absence of nominal rigidities while empirically estimated models generally use a gap measure defined as the deviation of output from a statistically estimated trend.

While shifts in trend productivity growth complicate the problem of estimating an output gap, a simple solution involves using the change in the estimate gap or an output growth variable. Gap changes appear to be more accurately measured in the sense that ex post revisions are both smaller and initial estimates of the change are not systemically related to the subsequent revisions. It is important not to ignore data uncertainty though. Orphanides and Williams (2002) consider the effects of varying the degree of uncertainty about the behavior of the natural rate of interest and the natural rate of unemployment. They argue that the costs of underestimating the degree of uncertainty are much larger than the costs of overestimating it. Thus, a risk-avoidance strategy would call for over-emphasizing the problem of data uncertainty and measurement errors. That is, the policy maker may be advised to use a deliberately distorted model that incorporates a higher level of uncertainty than is actually believed to characterize the data.

\section{Uncertainty about exogenous disturbances}

Data uncertainty is only one source of uncertainty. Another source arises from the behavior of economic disturbances. As Otmar Issing put it at last year's Jackson Hole conference, “...central

\footnotetext{
${ }^{14}$ The exception is Orphanides (2003a) who finds significant deterioration in policy outcomes when measurement error is incorporated. He employes an estimated backward-looking models and excludes the lagged interest rate from the policy rule.
} 
bankers are given little guidance as to the nature of the stochastic disturbances that drive the business cycle on average" (Issing, 2002, p. 184). The nature, source, and persistence of these disturbances may vary over time, and even when central banks are able to identify disturbances, uncertainty exists as to the persistence of the shocks. When the Asian financial crisis began in 1997, no one could know how long it would last or to how many countries it would spread. When the stock market bubble collapsed in 2000, no one could know how big the price drop would be nor how long it would take to recover.

A strategy for monetary policy that works well even in the absence of precise information on the characteristics of the disturbances is desirable. If such a strategy exists, it would allow the central bank to react in the same manner whether a disturbance was persistent or transitory. This means the central bank would not need to "get it right"; even if a disturbance initially expected to be quite transitory turned out to be much more persistent, the initial response would remain optimal.

Giannoni and Woodford (2002a, 2002b) and Svensson and Woodford (2003b) have proposed a class of "robust, optimal, explicit instrument rules" (ROE rules) that are explicit - they describe how the central bank's policy instrument should be adjusted in light of economic conditions. They are optimal - they succeed in minimizing the central bank's loss function, subject to the constraints imposed by the structure of the economy. They are robust - the optimal response to target variables such as inflation and the output gap is independent of both the variancecovariance structure of the disturbances and the serial correlation properties of the disturbances. Thus, structural changes in the economy reflected in changes in the behavior of the additive disturbances would not require the central bank to alter its policy rule.

In contrast, simple rules are not robust to changes in the behavior of the exogenous disturbances. The optimal coefficients in a simple rule depend on the variance-covariance structure 
and on their serial correlation properties. Thus, in the face of structural change in the pattern of disturbances, a central bank following a Taylor rule, for example, would need to re-optimize and adjust the way it responds to inflation and the output gap.

\section{Robustness and the data generating process}

To assess the gains from employing a robustly optimal explicit instrument rule, I compare its performance with ad hoc rules in the new Keynesian model employed in the previous section. Uncertainty about the processes followed by the exogenous disturbances is, in this simply framework, represented by uncertainty about the autocorrelation coefficients $\rho_{v}$ and $\rho_{e}$ and the relative variances of the innovations, $\sigma_{u}^{2} / \sigma_{\varepsilon}^{2}$.

The degree of serially correlation in structural disturbances is a source of controversy. Estrella and Fuhrer (2002) argue that the residual error term in structural equations should display zero serial correlation (i.e., $\rho_{e}=\rho_{v}=0$ ). But if this is the case, forward-looking relationships such as (3) and (4) cannot capture the dynamic behavior observed in the data. Rotemberg and Woodford (1997) and Ireland (2001) allow residual errors to be serially correlated and argue that forwardlooking models can match the data dynamics. Thus, there exists disagreement, at both the level of theoretical specification and at the empirical level over the true values of $\rho_{e}$ and $\rho_{v}$.

Suppose the central bank is able to commit. Under a fully optimal commitment policy, the central bank has an incentive to exploit the conditions existing at the time the policy is first adopted. That is, the rule the central bank would like to commit to follow in period $t+i, i>0$, will be different from the policy it will pick for period $t$. To avoid this inconsistency, Woodford (1999, 2002) has argued that commitment should be interpreted from what he has described as a timeless perspective (see also Svensson and Woodford 2003b). Under the timeless perspective, the central bank commits to a rule that it would have found optimal to commit to if it had chosen 
its policy at some earlier date. ${ }^{15}$ The timeless-perspective commitment policy that minimizes the loss function (5) subject to (3) and (4) is given by ${ }^{16}$

$$
i_{t}=\left(\frac{\kappa}{\sigma \beta}\right) i^{*}+\left(1+\frac{\kappa}{\sigma \beta}+\frac{1}{\beta}\right) i_{t-1}-\left(\frac{1}{\beta}\right) i_{t-2}+\left(\frac{\kappa}{\sigma \lambda_{i}}\right) \pi_{t}+\left(\frac{\lambda_{x}}{\sigma \lambda_{i}}\right)\left(x_{t}-x_{t-1}\right) .
$$

Implementing (8) corresponds to what Svensson (2003) labels a specific targeting rule. It is consistent with the first order condition obtained from the central bank's decision problem and therefore with the minimization of the bank's loss function. This instrument rule depends only on variables appearing in the central bank's objective function - inflation, the output gap, and the interest rate. The interest rate displays inertia, since history dependence improves the trade off between inflation and output variability. More importantly for our purposes, none of the coefficients appearing in (8) depend on $\rho_{v}, \rho_{e}$, or the variances of the disturbances. Hence, the optimal reaction to inflation, the change in the gap, or lagged interest rates depends only on the parameters characterizing the structural equations of the model $(\kappa, \sigma$, and $\beta)$ and those reflecting the relative weights of the objectives in the bank's loss function $\left(\lambda_{x}\right.$ and $\left.\lambda_{i}\right)$.

To assess the advantages of a ROE rule over simple rules, I focus on the role of $\rho_{e}$, the serial correlation in the inflation shock. As is well-known, this is the key disturbance generating policy trade-offs in a basic new Keynesian model. I ask two questions. First, how sensitive is performance under a simple rule to "getting it right"? That is, if it turns out that $\rho_{e}$ differs from the value on which the simple rule is based, how much does performance deteriorate? Second, if the policy maker is uncertain about the true value of $\rho_{e}$, should it error towards overestimating or underestimating it?

Four rules are considered. The first is a optimal Taylor rule of the form

$$
i_{t}=\alpha_{i} i_{t-1}+\alpha_{\pi} \pi_{t}+\alpha_{x} x_{t},
$$

\footnotetext{
${ }^{15}$ This assumes that central banks are not subject to the time-inconsistent preferences that seem to characterize individuals (Rabin 1998).

${ }^{16}$ See the appendix for the derivation.
} 
where the coefficients are chosen to minimize the loss function (5). ${ }^{17}$ The second rule, referred to as a fixed Taylor rule, holds the coefficients fixed at the values that are optimal for the benchmark calibrated values of $\rho_{e}$ and $\rho_{v}{ }^{18}$ The performance of this rule as the serial correlation of the disturbances varies provides a measure of the costs of mis-specification that would arise if the structure of disturbances changed but the central bank failed to re-optimize its instrument rule. The third policy rule is an optimal difference rule of the form

$$
i_{t}=i_{t-1}+\alpha_{\pi} \pi_{t}+\alpha_{\Delta x}\left(x_{t}-x_{t-1}\right) .
$$

The fourth rule is of the same form as (10) but with the coefficients held fixed at the values optimal for the baseline values of $\rho_{e}$ and $\rho_{v}$. Note that in this simple model, the ROE rule contains the same variables that appear in the difference rule, with the sole addition of the second lag of the nominal interest rate. ${ }^{19}$ Hence, we should not be surprised if the difference rule does well in this version of the model.

Figure 2 shows the loss under each rule expressed as the percent increase over the ROE rule as a function of $\rho_{e}$. Focusing first on the Taylor rules, two points stand out. First, performance tends to deteriorate relative to the ROE rule as $\rho_{e}$ increases until $\rho_{e}$ reaches 0.8 , at which point the optimal Taylor rule improves relative to the ROE rule. Second, a failure to reoptimize the Taylor rule coefficients carries very little cost if the shock is not very persistent (the cost of not reoptimizing is below $20 \%$ for $\left.\rho_{e}<0.7\right)$ but a large cost if the shock turns out to be very persistent. Interestingly, if the coefficients are held fixed at the values optimal for a much larger value of $\rho_{e}$ than 0.35 , the outcomes under a fixed Taylor rule deteriorate less for either very large or very small values. This can be seen in figure 3 which illustrates the outcomes under Taylor rules optimized for $\rho_{e}=0.35$ and for $\rho_{e}=0.70$. Overestimating the persistence of the

\footnotetext{
${ }^{17}$ I now ignore the problem of data uncertainty.

${ }^{18}$ Following Giannoni and Woodford, the baseline calibration sets $\rho_{e}=\rho_{v}=0.35$.

${ }^{19}$ I normalize $i^{*}$ by setting it equal to zero.
} 
inflation shock limits the maximum loss (relative to the optimal Taylor rule) if the central bank is uncertain about the true value of $\rho_{e}$.

Difference rules do extremely well over the entire range of $\rho_{e}$ (see figure 2). Even though the coefficients of the difference rule are also functions of $\rho_{e}$, the costs of ignoring this dependence and simply using fixed response coefficients are trivial. Perhaps this is not surprising since the difference rule is quite similar to the ROE rule in this model. ${ }^{20}$

To summarize, there is essentially no deterioration under a fixed difference rule that gets $\rho_{e}$ wrong; failing to re-optimize as the disturbance process changes, or incorrectly estimating the true value of $\rho_{e}$ causes only a relatively small increase in the loss function. The Taylor rule is not as robust as the difference rule; incorrectly estimating the true values of $\rho_{e}$ can cause a large increase in the loss function. However, intentional overestimating the degree of persistence in the inflation process can serve to limit the costs of uncertainty about $\rho_{e}$ under a Taylor rule.

\section{Parameter uncertainty}

The previous subsection discussed uncertainty concerning the processes generating the exogenous, additive disturbance terms. Central banks also face uncertainty about the structural parameters that appear in their economic model. In contrast to uncertainty about the additive disturbances, parameter uncertainty creates multiplicative uncertainty.

The classic work by Brainard (1967) concluded that a policy maker should act more cautiously in the face of multiplicative uncertainty. The intuition for this result is straightforward, and Blinder (1998) has suggested that it captures the approach of actual policy makers. However, Craine (1979) showed that uncertainty about model dynamics can lead policy to react more aggressively, a result also obtained by Söderström (2002). To understand the intuition for this

\footnotetext{
${ }^{20}$ The two will differ more significantly when inflation inertia is incorporated into the model. See section 4.
} 
finding, suppose the impact of current inflation on future inflation is uncertain. Any variability in the coefficient on current inflation in the equation for future inflation amplifies the impact that variability in current inflation has on future inflation. It will pay to make sure current inflation is very stable by reacting more aggressively to shocks.

Dynamics are not necessary to overturn Brainard's basic result however. To illustrate this point, suppose the simple model used in the previous section is modified to take the form

$$
\begin{gathered}
x_{t}=E_{t} x_{t+1}-s_{t}\left(i_{t}-E_{t} \pi_{t+1}-r_{t}^{n}\right) \\
\pi_{t}=\beta E_{t} \pi_{t+1}+\kappa_{t} x_{t}+e_{t} .
\end{gathered}
$$

In contrast to equations (3) and (4), the coefficients $s$ and $\kappa$ are allowed to be stochastic. ${ }^{21}$ For simplicity, assume that $s_{t}$ and $\kappa_{t}$ are independently distributed, i.i.d., with known means and variances $(\bar{s} \bar{\kappa})$ and $\left(\sigma_{s}^{2} \sigma_{k}^{2}\right)$. Assume the policy maker observes $r_{t}^{n}$ and $e_{t}$ prior to setting the nominal interest rate but does not observe the current realizations of $s_{t}$ or $\kappa_{t}$. The objective of the central bank is to minimize the loss function given by (5). ${ }^{22}$ It can be shown that the nominal interest rate under optimal discretion is given by

$$
i_{t}=\frac{\lambda_{i} i^{*}+\bar{s}\left(\bar{\kappa}^{2}+\sigma_{\kappa}^{2}+\lambda_{x}\right) r_{t}^{n}-\bar{s} e_{t}}{\left(\bar{s}^{2}+\sigma_{s}^{2}\right)\left(\bar{\kappa}^{2}+\sigma_{\kappa}^{2}+\lambda_{x}\right)+\lambda_{i}}=a_{0}+a_{1} r_{t}^{n}-a_{2} e_{t}
$$

Consider first uncertainty about $s_{t}$, the interest rate elasticity of output. The variance of $s$ appears only in the denominator of (13). This is the classic Brainard result - the interest rate is adjusted less in the face of either natural interest rate or cost shocks than would be optimal

\footnotetext{
${ }^{21}$ The interest elasticity of demand was previously denoted by $1 / \sigma$; it is more convenient to specify parameter uncertainty in terms of $s \equiv 1 / \sigma$.

${ }^{22}$ If the loss function is interpreted as an approximation to the welfare of the representative agent, uncertainty about $s$ and $\kappa$ would also imply the policy maker is uncertainty about the correct values of $\lambda_{x}$ and $\lambda_{i}$. I follow the existing literature and ignore this complication. Levin and Williams (2003b) incorporate this additional aspect into an analysis of uncertainty.
} 
if $s$ were known with certainty. Similarly, an increase in the variance of $\kappa$ reduces the interest rate response to cost shocks. However, the situation is different if we consider the reaction to $r_{t}^{n}$ when the value of $\kappa$ is uncertain. If $\lambda_{i}=0$, then $\bar{\kappa}^{2}+\sigma_{\kappa}^{2}+\lambda_{x}$ cancels from the coefficient on $r_{t}^{n}$ and uncertainty about $\kappa$ has no effect on the optimal response to $r_{t}^{n}$. That is, regardless of how uncertain the central bank is about the response of inflation to output movements, it should attempt to neutralize the impact of demand shocks on output. Parameter uncertainty about $\kappa$ only makes failure to do so more costly. When the central bank cares about interest rate volatility, however, it will not fully neutralize demand shocks, and the optimal response to such shocks is affected by $\sigma_{\kappa}^{2}$. In fact,

$$
\frac{\partial a_{1}}{\partial \sigma_{\kappa}^{2}}=\frac{\bar{s} \lambda_{i}}{\left(\bar{s}^{2}+\sigma_{s}^{2}\right)\left[\left(\bar{\kappa}^{2}+\sigma_{\kappa}^{2}+\lambda_{x}\right)+\lambda_{i}\right]^{2}}>0
$$

Increased uncertainty about $\kappa$ leads, under optimal discretion, to a more aggressive response to the natural rate of interest as long as $\lambda_{i}>0$. The intuition for this result lies in the consequences of failing to respond aggressively to fluctuations in $r^{n}$. The effect of output fluctuates on the variance of inflation is reinforced by the variability of $\kappa$; thus, to stabilize inflation the central bank wants to move more aggressively to limit the impact of $r^{n}$ on the output gap.

Absent conclusive theoretical predictions, the impact of parameter uncertainty must be assessed within the context of specific models. This has been done by a number of authors. For example, Rudebusch (2002) allows for parameter uncertainty in an estimated, backward-looking model. He finds that the coefficients in an optimal simple Taylor rule are only marginally affected by parameter uncertainty, a finding consistent also with those of Estrella and Mishkin (1999). In reviewing other research on parameter uncertainty, Rudebusch concludes that only when policy is characterized by a "many-parameter unrestricted policy rule" and the model economy is represented by an unrestricted VAR are large effects found.

The illustrative example leading to equation (13) adopted a Bayesian perspective; policy was 
designed to minimize expected loss, where expectations were taken with respect to the joint distribution of the additive disturbances and the unknown parameters. This approach requires that the central bank formulate a prior probability distribution that reflects the uncertainty it faces. An alternative approach is to assess the consequences of basing policy on incorrect values of key parameters. That is, suppose the central bank faces uncertainty about the true value of some parameter $\gamma$. Suppose the policy maker believes the true value is $\hat{\gamma}$ when the actual value is $\gamma$. Are there combinations of $\gamma$ and $\hat{\gamma}$ that lead to particularly bad outcomes?

To investigate this question, I focus on the degree of inertia in the inflation process.

\section{Inertia in the inflation process}

The existing literature has identified the degree of endogenous inertia in the inflation process as one of the most critical parameters affecting the evaluation of alternative policies. For example, Rudebusch (2002) found that nominal income targeting does well when inflation is forward-looking but poorly when it is more backward-looking. Similarly, when current inflation is affected by both expected future inflation and lagged inflation, the performance of price-level targeting deteriorates significantly as the relative weight on lagged inflation rises (Walsh 2003a). Levin and Williams (2003a) demonstrate that policy rules that are optimal in a forward-looking model can lead to disastrous results if the true model is in fact backward-looking.

Unfortunately, given the significance it has for the evaluation of alternative regimes, there is great uncertainty about the respective roles of forward and backward elements in the inflation process. For example, Rudebusch (2002) using an output gap measure based on de-trended output estimates that the weight on lagged inflation is over twice that on expected future inflation, while Galí and Gertler (1999), using a measure of real marginal cost rather than the output gap, find just the reverse.

To incorporate an effect of lagged inflation on current inflation, I follow the specification 
of Giannoni and Woodford. They assume that a fraction of all firms are randomly selected to optimally adjust their price, while the remaining fraction, rather than keeping their prices fixed, adjust them by a fraction $\phi$ of the most recent period's actual rate of inflation. Woodford (2002) shows that this specification implies that the inflation process is given by

$$
\pi_{t}-\phi \pi_{t-1}=\beta\left(E_{t} \pi_{t+1}-\phi \pi_{t}\right)+\kappa x_{t}+e_{t}
$$

Galí and Gertler (1999) find a weight on lagged inflation of around 0.3, suggesting a value of 0.5 for $\phi$, and this is the value I use for the baseline calculations. ${ }^{23}$

Consider the problem of minimizing the loss function (5) subject to the expectational IS curve (3) and the inflation adjustment equation (14). ${ }^{24}$ I again focus on the ROE, Taylor, and difference rules. For each rule, I compare outcomes when the coefficients in the rules are adjusted optimally as $\phi$ varies and when the rules are optimal for a fixed $\hat{\phi}$ but are not adjusted as $\phi$ varies. $^{25}$

Before examining the outcome of this comparison, one further comment needs to be made concerning the difference rule and the ROE rule. When $\phi=0$, the difference rule and the ROE rule both called for responding to the lagged interest rate, inflation, and the change in the gap. The ROE rule also included the second lag of the interest rate, but the basic similarity of the two rules meant that we might expect them to perform similarly, as in fact turned out to be the case.

\footnotetext{
${ }^{23}$ Erceg and Levin (2003) find that the inertia in the inflation can arise due to shifts in the central bank's policy rule. Thus, in evaluating the effects of alternative rules under commitment, it seems appropriate to use a relatively more forward-looking specification.

${ }^{24}$ Woodford (2002) demonstrates that the presence of lagged inflation in the inflation adjustment equation also affects the form of the loss function. However, given the general acceptance of (5), I ignore this connection and continue to use (5) to represent the policy maker's objective.

${ }^{25}$ The optimal ROE can be found analytically (see the appendix). The coefficients in the optimal Taylor and difference rules are found numerically.
} 
When $\phi \neq 0$, the differences between the two rules becomes more pronounced. The ROE rule now involves additional lags of the interest rate, the expected future value of the interest rate, and the expected future output gap. The appendix shows that under the optimal precommitment policy, the nominal interest rate must satisfy

$$
\begin{aligned}
\Omega i_{t}= & \phi \beta E_{t} i_{t+1}+\left[1+\phi+\frac{1}{\beta}\left(\frac{\kappa}{\sigma}+1\right)\right] i_{t-1}-\left(\frac{1}{\beta}\right) i_{t-2}-\left(\frac{\kappa}{\sigma \lambda_{i}}\right) \pi_{t} \\
& +\left(\frac{\lambda_{x}}{\sigma \lambda_{i}}\right)\left[(1+\phi \beta) x_{t}-x_{t-1}-\phi \beta E_{t} x_{t+1}\right]+\left(\frac{\kappa}{\sigma \beta}\right) i^{*}
\end{aligned}
$$

where $\Omega=1+\phi(1+\beta) .{ }^{26}$ When $\phi>0$, the difference rule and the ROE rule can differ significantly, so it is no longer immediately obvious how well the difference rule will perform relative to the ROE rule.

Figure 4 illustrates the loss under the various rules, expressed as the percent increase relative to the loss under the ROE rule. Notice that a Taylor rule does worse than either the ROE rule or the difference rule. For no value of $\phi$, however, is the loss under even the inefficient, fixed Taylor rule more than $35 \%$ greater than under the optimal ROE rule. All the rules, including the ROE rule based on $\hat{\phi}=0.5$, deteriorate as $\phi$ approaches 1 .

Figure 5 shows the outcomes for the Taylor and difference rules if the central bank bases the rule on an estimate of $\phi$ that is either smaller $(\hat{\phi}=0.25)$ or larger $(\hat{\phi}=0.75)$ than the "true" value $(\phi=0.5)$. For the Taylor rule, overestimating the degree of backward-looking dynamics in the inflation process leads to more robust outcomes. The same is also true of the difference rule, but for this rule, the costs of getting the value of $\phi$ correct are small. Again, however, overestimating the persistence in the inflation process results in a more robust rule than is obtained if the persistence is underestimated.

These results suggest that policy makers should act as if inflation were more backward-looking

\footnotetext{
${ }^{26}$ This differs from the result in Giannoni and Woodford (2002b) as they also alter the loss function to be consistent with the inertia in the inflation process.
} 
than they perhaps actually believe it is. However, the results also illustrate that notions of cautious and aggressive reaction in the face of parameter uncertainty are both model and rule specific. If the central bank's strategy is to follow a Taylor rule, then the responses to inflation and the output gap fall if $\hat{\phi}$ is increased; if a difference rule is followed, the response coefficients increase.

In the benchmark model employed in this section, simple Taylor rules and first difference rules performed well, even when based on incorrect values of certain key parameters. Thus, a strategy of using such rules as guidelines for monetary policy may not be too costly in the face of structural change, even if response coefficients are not fully optimal. However, Levin and Williams (2003a) caution against drawing conclusions based on a single reference model as is done here, but they do conclude that simple rules can be found that are robust across a range of model. In a finding that can be interpreted as consistent with figure 5, Levin and Williams find that policies obtained from a backward-looking model are the most robust when used in competing models. This result also suggests that a policy maker concerned with robustness might wish to overestimate inflation inertia.

\section{Robust control}

The notion that policy may be more robust if based on a systematically distorted model of the economy is a key implication of the recent literature on robust control. The robust control approach proceeds from the assumption that the central bank has a model of the economy that it believes is a reasonable approximation to the true model but that this approximating model may be subject to mis-specification (Hansen and Sargent 2003, 2004). ${ }^{27}$ Rather than viewing the

\footnotetext{
${ }^{27}$ For other approaches to robust control see Onatski and Stock (2002), Onatski and Williams (2003), and Onatski (no date), and Stock (1999).
} 
set of possible mis-specifications as simply random, the policy maker assumes "nature" is an evil agent who will choose the mis-specification that makes the policy maker look as bad as possible. In such an environment, optimal policy aims to minimize the worst-case outcome that could arise.

Suppose the central bank's perceived or reference model is

$$
y_{t+1}=\bar{A} y_{t}+\bar{B} i_{t}+\bar{C} e_{t+1}
$$

The bank recognizes this model is subject to error, with the true model given by

$$
y_{t+1}=\bar{A} y_{t}+\bar{B} i_{t}+\bar{C}\left(e_{t+1}+w_{t+1}\right)
$$

The difference between the central bank's reference model and the true model is represented by $\bar{C} w_{t+1}$. In the robust control approach, $w_{t+1}$ is not treated simply as an additive, exogenous disturbance like $e_{t+1}$. Instead, it may depend on the history of $y_{t}$ and can therefore encompass a wider set of possible mis-specifications, as indicated earlier in equation (2).

The policy maker is assumed to view (16), the case when $w_{t+1}=0$, as a good "approximating model" to the true but unknown model. It is a good approximation in the sense that the possible model mis-specification errors are bounded:

$$
\sum_{i=0}^{\infty} \beta^{i} w_{t+i}^{\prime} w_{t+i} \leq \eta_{0}, \quad \eta_{0}>0
$$

The value of $\eta_{0}$ determines how far away from the true model the central bank's reference model might be. The standard case of complete model certainty corresponds to $\eta_{0}=0$; in this case, the central bank's approximating model is equal to the true model. When $\eta_{0}>0$, equation (18) imposes a limit on the size of the specification errors the central bank believes are possible.

Hansen and Sargent (2004) discuss two alternative interpretations of optimal, robust policy. The first interpretation is that the central bank has standard preferences but optimizes using a purposefully distorted view of the economy. The second interpretation is one in which the central 
bank's model is not distorted, but instead the preferences of the central bank reflect an increased sensitivity to risk.

\section{Policy using a distorted model}

Under the first interpretation, the central bank replaces the model of the economy with a distorted model, one that incorporates the worst-case process for $w_{t+1}$. The value of $w_{t+1}$ for which the worst-case outcome occurs will be a function of the state vector, $K y_{t} \cdot{ }^{28}$ The vector $K$ reflects the way model mis-specification is endogenous.

Substituting $w_{t+1}=K y_{t}$ into (17) yields

$$
y_{t+1}=(\bar{A}+\bar{C} K) y_{t}+\bar{B} i_{t}+\bar{C} e_{t+1}
$$

Equation (19) represents the distorted model. The central bank now treats this distorted model as if it were the true model of the economy. The policy problem based on the distorted model is now standard and involves minimizing loss subject to (19).

This interpretation of robust control highlights its contrast to the standard Bayesian approach. A Bayesian central bank, faced with model uncertainty, assigns a probability to each possible model, where these probabilities reflect the central bank's assessment of the likelihood of each model. In contrast, a central bank concerned with robustness bases policy on a distorted model, as in (19), but then acts as if there were no longer any model uncertainty. The distorted model reflects the worst-case model the central bank could face, and, given that worse case, it optimally determines policy.

In a number of cases that have been analyzed, the worst-case model is characterized by increased persistence. This result is consistent with the findings discussed in section 3 and 4; the

\footnotetext{
${ }^{28}$ The situation is more complicated when the model involves forward-looking expectations. In that case, $w_{t+1}$ also depends on the Lagrangian multipliers associated with the forward-looking variables. See Hansen and Sargent (2003).
} 
dangers of underestimating the degree of persistence appear to be greater than those of overestimating persistence. The nature of the distorted model a policy maker uses under robust control is illustrated in figure 6, which shows, for the new Keynesian model of section 4, the difference between the inflation shock in the worst-case model and the approximating model. ${ }^{29}$ The worst case involves a larger and more persistent inflation shock. From the basic new Keynesian inflation adjustment equation, current inflation can be expressed as equal to the present discount value of current and future expected output gaps and inflation shocks. Under the worst case model, the present value of the shock is larger, leading to a larger immediate response of inflation. To protect against this possibility, the central bank raises interest rates more under the robust policy, and, as a consequence, the output gap initially declines more sharply than under the standard optimal commitment policy (see figure 7). If the worst case does occur, the output gap declines significantly; under the approximating model, the output gap rebounds quickly.

From the perspective of policy strategies, the use of a distorted model has several problems. Basing forecasts on a model that the policy maker knows is distorted would make it more difficult to communicate the rationale behind policy actions. It also eliminates the separation between the forecasters and the decision makers. The distorted model (19) depends on $K$, the policy rule of the evil agent. But the worst-case outcome clearly depends on the relative weights the policy maker places on the various goals in the objective function. Thus, the forecaster needs to incorporate the policy maker's preferences into the forecasting exercise in ways that violate an important separation between decisions and the advice on which they are based.

Svensson (2000) argues that worst-case outcomes are likely to be low probability events. As a consequence, a robust policy is, from a Bayesian perspective, too heavily influenced by such events. For example, Giannoni (2002) finds that as long as the natural rate of interest is not too

\footnotetext{
${ }^{29}$ Parameter values are those reported in Table 1 , with $\phi=0.5$. To obtain the impulse response functions, I used the programs developed by Girodani and Söderlind (2003).
} 
highly serially correlated, a robust policy involves acting as if the output elasticity of inflation takes on its largest possible value. Thus, the robust policy is sensitive to assumptions made about the largest or smallest possible values a parameter can take on. For most model parameters, it is more likely that a central tendency and some assessment of its variability can be made than that the possible extreme values can be delineated.

\section{Preferences}

A second interpretation of robust control makes a connection between robust policies and the form of the policy maker's preferences. The same policy that results from a central bank employing the distorted model (19) is obtained when the central bank takes its approximating model (16) as the true model and maximizes an objective function that reflects an additional sensitivity to risk.

Specifically, Hansen and Sargent (2004) show that robust policies can be obtained if the central bank evaluates outcomes according to the fixed point $U_{0}$ of

$$
U_{t}=-r\left(\pi_{t}, x_{t}\right)+\left(\frac{2}{\chi}\right) \log E\left[\exp \left(\frac{\chi U_{t+1}}{\beta 2}\right)\right]
$$

where $r\left(\pi_{t}, x_{t}\right)$ is a quadratic loss function depending on inflation and the output gap and $\chi \leq$

$0 .^{30}$ The parameter $\chi$ reflects additional risk sensitivity; when $\chi=0$ one obtains the standard specification. Thus, robust policy arises if the policy maker ignores model uncertainty (i.e., treats 16 as the true model) but has preferences described by (20).

Under the preference interpretation, the construction of a set of forecasts for the goal variables and the choice among the alternative paths is again separated. If the policy maker has risk sensitive preferences, that fact will affect which instrument path is chosen as most preferred.

\section{Precautionary policies}

\footnotetext{
${ }^{30}$ Similar risk sensitive preferences have been studied by Epstein and Zin (1989) and Weil (1990).
} 
When applied to the study of household saving behavior, risk sensitive preferences lead to precautionary saving. For example, Hansen and Sargent (2004) analyze Hall's model of consumption and demonstrate that a preference for robustness is equivalent to altering the subjective discount factor to give more weight to future expected utility. A consumer with risk sensitive preferences, therefore, will want to tilt his or her consumption profile by reducing current consumption. By reducing current consumption and accumulating more wealth, the consumer is able to better insure against a future bad wealth shock.

Similarly, a risk sensitive central bank would engage in precautionary policies. Risk sensitive preferences imply that the central bank is not indifferent to the question of when uncertainty is resolved. It is willing to take a policy action today that removes the possibility of a future bad outcome, even if the current cost exceeds the expected discounted future cost because the bad outcome is a low probability event.

The most relevant current application of the notion of precautionary policies is to the possibility of a costly deflation and/or of encountering the zero lower bound on nominal interest rates. A risk sensitive policy maker would engage in a more expansionary policy today to avoid these potential problems than would an expected utility maximizer. A central bank following a robust policy will cut interest rates more aggressively in the face of a negative inflation shock because in the worst-case scenario these shocks turn out to be more persistent than in the approximating model (see figure 6). Thus, a desire for robust does call for more aggressive interest rate cuts to protect against the possibility that the economy is pushed into a deflation.

A desire for robustness and the associated tendency to engage in precautionary policies can be rationalized within the framework of the robust control approach. The preference interpretation of robust control then raises the issue of whether policy makers actually do display a desire for robustness, as well as the critical issue of whether they should display such a desire. 


\section{Whose preferences should central banks reflect?}

One theme in recent work on monetary policy is that the objectives of the central bank should be tied to the welfare of individuals in the economy. This means that the weights in a loss function such as (5) should be functions of individuals' attitudes towards risk, as well as the costs of nominal rigidities.

Standard economic theory assumes individual are expected utility maximizers. Yet there is a large body of research in both psychology and experimental economics that casts doubt on expected utility theory as a description of individual behavior. For example, evidence from psychology finds that individuals are ambiguity averse, reflecting a more severe dislike of uncertainty - being faced with choices involving unknown or subjective uncertainties - than of risk - choices involving known or objective uncertainties. Individuals are not indifferent to the timing by which uncertainty is resolved, and they tend to place a disproportionately large weight on vivid evidence. This means that observing a phenomena such as deflation in Japan may assume a much larger place among policy concerns that would be warranted by more objective evaluations.

Standard theory also assumes policy makers minimize an expected discounted loss function. Exponential discounting implies that intertemporal preferences are time-consistent - the way in which the central bank would trade-off output and inflation between period $t+1$ and $t+2$ from the perspective of time $t$ will remain the same at time $t+1$ if the only thing that has changed is that we are one period closer to $t+2$. However, research in psychology provides ample evidence that individuals do not exponentially discount future utility. ${ }^{31}$ Instead, they display a preference for immediate gratification. A policy maker that correctly reflected the preferences of such a representative agent would be willing to trade-off some inflation for an economic expansion today even thought it would, in all honesty, claim it would not do so in the future.

\footnotetext{
${ }^{31}$ For a survey of some of the psychology research relevant for economics, see Rabin (1998).
} 
There are contexts in which distorting the central bank's preferences away from those of the public can improve policy outcomes. Social welfare depends on a long list of attributes, including factors such as health, education, and security. Yet we do not expect nor desire central banks to treat these as among its objectives. One interpretation of inflation targeting or other targeting regimes is that they represent policy environments in which the central bank's objectives are distorted away from those of the representative agent. The objective in so doing is to offset policy biases that can arise if the central bank acts under discretion. For example, Rogoff (1985), Walsh (1995), and Svensson (1997) focused on how the central bank's objectives could be distorted to eliminate any potential for an average inflation bias due to problems of time inconsistency. Jensen (2002), Vestin (2000), and Walsh (2003a) investigate how the assignment of policy targets can reduce a stabilization bias that also arises under discretionary policies in forward-looking models. The best way to maximize social welfare may not be for the central bank to maximize social welfare.

Policy makers may be risk sensitive; in that case, robust control should allow for a better positive theory of actual policy decisions. But in designing monetary policy strategies, should central banks act as if they had risk sensitive preferences? Sims (2001) argues that the max-min approach of robust control may provide a shortcut for decision making that may be appropriate for a private individual "buying a washing machine" but would be inappropriate as a shortcut for policy makers. Sims labels such preferences as "subrational." If we require that policy makers have intertemporally time-consistent preferences and that they be indifferent to the timing by which uncertainty is resolved, then preferences can be represented by expected utility (Chew and Epstein 1989). But there is nothing irrational or subrational in preferring an early resolution of uncertainty; early resolution may allow for better planning, for example. In this case, there will be precautionary aspects to optimal policy. 
Economists have traditionally focused primarily on exploring the implications of alternative monetary policies, leaving policy makers (or economists serving as policy makers) to decide which policy to pursue. Recent work has stressed the link between the objectives policy makers should pursue and both the structure of the economy and the preferences of the individuals populating the model economy. This link will need to be investigated more fully before we can conclude whether policy makers should display a desire for robustness or not.

\section{Conclusions}

Are there some simple guidelines for policy makers faced with model uncertainty? While any recommendations risk being model specific, I draw these conclusions:

1. Simple rules can play a useful role as guidelines for policy makers. The form of the policy rule can matter, however. Uncertainty about the level of the output gap suggests using a first difference rule.

2. Uncertainty about the behavior of the exogenous disturbances affects simple rules in principle, but in practice such rules appear to be fairly robust to mis-specification of the error processes. Difference rules perform about as well as the robust, optimal, explicit instrument rules that are specifically designed to be robust with respect to the processes governing exogenous disturbances.

3. In a Bayesian framework, parameter uncertainty has no general implications for how response coefficients should changed. An informal approach to robustness suggests policy makers should error on the side of treating disturbances as quite persistence and the inflation process as backward-looking.

4. In a formal robust control framework, policy is based on a distorted model of the econ- 
omy. This distorted model serves also to ensure the policy maker takes precautions against persistent shocks. Because the way the model should be distorted depends on the policy makers preferences, the separation between the task of the economist in preparing forecasts and the policy maker in making choices is blurred.

5. Robust policies using a distorted model are equivalent to those arising when the central bank treats its reference model as if it were the true model but uses risk sensitive preferences in choosing its policy. A risk sensitive policy maker will undertake precautionary policies.

Finally, the work of Levin and Williams (2003a) offers a cautionary tale for any attempt to draw firm conclusions based, as is done here, on a single model. They show that policies that are optimal in one model may perform poorly or even produce dynamic instability in another model. One important distinction between the various models employed in monetary policy analysis is the extent to which they emphasize forward-looking expectations. Theory-based models typically imply such expectations should be of critical importance, but empirically based models contain important elements of backward-looking behavior. While not disputing the better 'fit' of these models, I believe they are likely to be less informative about the impact of alternative policies than forward-looking models will be. The policies analyzed in this paper assume the central bank is able to commit to specific policy rules; it seems unreasonable, at least to me, to assume agents' expectations do not adjust across different policy regimes in ways that affect the dynamic behavior of the economy. 


\section{Appendix: Optimal commitment from the timeless perspec- tive}

Giannoni and Woodford (2002b) derive the robust, optimal, explicit instrument rule when both the inflation adjustment equation and the loss function are altered to reflect partial indexation to lagged inflation. Since I maintain equation (5) as the loss function when incorporating lagged inflation into the inflation adjustment equation, the derivation of the ROE rule differs from the one they obtain.

The decision problem of the central bank under commitment can be written as

$$
\begin{aligned}
& \max E_{t} \sum_{i=0}^{\infty} \beta^{i}\left\{\pi_{t+i}^{2}+\lambda_{x} x_{t+i}^{2}+\lambda_{i}\left(i_{t+i}-i^{*}\right)^{2}\right. \\
& +s_{1 t+i}\left[x_{t+i}-E_{t+i} x_{t+i+1}+\left(\frac{1}{\sigma}\right)\left[i_{t+i}-E_{t+i} \pi_{t+i+1}-r_{t+i}^{n}\right]\right] \\
& \left.+s_{2 t+i}\left[\pi_{t+i}-\left(\frac{\beta}{1+\phi \beta}\right) E_{t+i} \pi_{t+i+1}-\left(\frac{\phi}{1+\phi \beta}\right) \pi_{t+i-1}-\left(\frac{\kappa}{1+\phi \beta}\right) x_{t+i}-\left(\frac{1}{1+\phi \beta}\right) e_{t+i}\right]\right\}
\end{aligned}
$$

The first order conditions for this problem are

$$
\begin{gathered}
\pi_{t}-\beta^{-1}\left(\frac{1}{\sigma}\right) s_{1 t-1}+s_{2 t}-\left(\frac{1}{1+\phi \beta}\right) s_{2 t-1}-\beta\left(\frac{\phi}{1+\phi \beta}\right) E_{t} s_{2 t+1}=0 \\
\lambda_{x} x_{t}+s_{1 t}-\left(\frac{1}{\beta}\right) s_{1 t-1}-\left(\frac{\kappa}{1+\phi \beta}\right) s_{2 t}=0
\end{gathered}
$$

and

$$
\lambda_{i}\left(i_{t}-i^{*}\right)+\left(\frac{1}{\sigma}\right) s_{1 t}=0
$$

Assume the policy has been in place for at least two periods. ${ }^{32}$ Then, using (23) to eliminate $s_{1 t}$ and $s_{1 t-1}$ from (22) and solving for $s_{2 t}$ yields

$$
s_{2 t}=\left(\frac{1+\phi \beta}{\kappa}\right)\left[\lambda_{x} x_{t}-\sigma \lambda_{i}\left(i_{t}-i^{*}\right)+\beta^{-1} \sigma \lambda_{i}\left(i_{t-1}-i^{*}\right)\right] .
$$

\footnotetext{
${ }^{32}$ This assumption imposes the timeless perspective on the optimal policy.
} 
Rewrite (21) using (23) as

$$
\pi_{t}+\beta^{-1} \lambda_{i}\left(i_{t-1}-i^{*}\right)+\left(\frac{1}{1+\phi \beta}\right) \Delta s_{2 t}-\left(\frac{\phi \beta}{1+\phi \beta}\right) \Delta s_{2 t+1}=0
$$

where $\Delta=1-L$ and $L$ is the lag operator. Using (24) to eliminate the Lagrangian multiplier $s_{2}$ from this last expression yields

$$
\begin{aligned}
\pi_{t}= & -\beta^{-1} \lambda_{i}\left(i_{t-1}-i^{*}\right)+\left(\frac{1}{\kappa}\right)\left[\lambda_{x} \Delta x_{t}-\sigma \lambda_{i} \Delta i_{t}+\beta^{-1} \sigma \lambda_{i} \Delta i_{t-1}\right] \\
& -\left(\frac{\phi \beta}{\kappa}\right)\left(\left[\lambda_{x} \Delta E_{t} x_{t+1}-\sigma \lambda_{i} \Delta E_{t} i_{t+1}+\beta^{-1} \sigma \lambda_{i} \Delta i_{t}\right]\right.
\end{aligned}
$$

This last equation can be written as

$$
\left(\frac{\sigma \lambda_{i}}{\kappa}\right)\left\{\phi \beta E_{t} i_{t+1}-[1-\phi(1+\beta)] i_{t}+\left[1+\phi+\beta^{-1}\left(\frac{\kappa}{\sigma}-1\right)\right] i_{t-1}-\left(\frac{1}{\beta}\right) i_{t-2}\right\}=q_{t}
$$

where

$$
q_{t} \equiv \pi_{t}-\left(\frac{\lambda_{x}}{\kappa}\right)\left(\Delta x_{t}-\phi \beta \Delta x_{t+1}\right)-\frac{\lambda_{i}}{\beta} i^{*}
$$

This yields equation (15) of the text. Setting $\phi=0$ yields equation (8). 


\section{References}

[1] Aoki, K., "On the Optimal Monetary Policy Response to Noisy Indications," Journal of Monetary Economics, 50(3), April 2003, 497-523.

[2] Bernanke, B. S. and J. Boivin, "Monetary Policy in a Data-Rich Environment," Journal of Monetary Economics, 50(3), April 2003, 525-546.

[3] Blinder, A. S., Central Banking in Theory and Practice, Cambridge: MIT Press, 1998.

[4] Brainard, W., "Uncertainty and the Effectiveness of Policy," American Economic Review, 57(2), May 1967, 411-425.

[5] Bridgeman, B., Psychology and Evolution: The Origins of the Mind, Sage Publications, 2003.

[6] Chew, S. H. and L. G. Epstein, "A Unifying Approach to Axiomatic Non-expected Utility Theories," Journal of Economic Theory, 49(2), 1989, 207-240.

[7] Craine, R., "Optimal Monetary Policy with Uncertainty," Journal of Economic Dynamics and Control 1(1), Feb. 1979, 59-83.

[8] Ehrman, M. and F. Smets, "Potential Output Gap Uncertainty: Implications for Monetary Policy," Journal of Economic Dynamics and Control, 2002.

[9] Epstein, L. G. and S. E. Zin, "Substitution, Risk Aversion, and the Temporal Behavior of Consumption and Asset Returns: A Theoretical Framework," Econometrica, 57(4), July 1989, 937-969.

[10] Erceg, C. J. and A. T. Levin, "Imperfect Credibility and Inflation Persistence," Journal of Monetary Economics, 50(4), May 2003, 915-944. 
[11] Estrella, A. and J. C. Fuhrer, "Dynamic Inconsistencies: Counterrfactual Implications of a Class of Rational Expectations Models," American Economic Review, 92(4), Sept. 2002, 1013-1028.

[12] Estrella, A. and F. S. Mishkin, "Rethinking the Role of NAIRU in Monetary Policy: Implications of Model Formulation and Uncertainty," in Monetary policy Rules, J. B. Taylor, ed., Chicago: The University of Chicago Press, 1999, 405-430.

[13] Galí, J. and M. Gertler, "Inflation Dynamics: A Structural Econometric Investigation," Journal of Monetary Economics, 1999, 44, 195-222.

[14] Gaspar V. and F. Smets, "Monetary Policy, Price Stability and Output Gap Stabilization," International Finance, 5(2), 2002, 193-211.

[15] Gerali, A. and F. Lippi, "Optimal Control and Filtering in Linear Forward-Looking Economics: A Toolkit," Aug. 2002.

[16] Giannoni, M., "Does Model Uncertainty Justify Caution? Robust Optimal Monetary Policy in a Forward-Looking Model," Macroeconomic Dynamics 6(1): 111-144, February 2002.

[17] Giannoni, M. and M. Woodford, "Optimal Interest-Rate Rules: I. General Theory," Princeton University, Aug. 2002a.

[18] Giannoni, M. and M. Woodford, "Optimal Interest-Rate Rules: II. Applications," Princeton University, Aug. 2002b.

[19] Giordani, P. and P. Söderlind, "Solution of Macromodels with Hansen-Sargent Robust Policies: Summary and Some Extensions," May 2002.

[20] Gramlich, E. M. "Remarks," Wharton Public Policy Forum Series, Philadelphia, PA. April $22,1999$. 
[21] Hansen, L. P. and T. J. Sargent, "Robust Control for Forward Looking Models," Journal of Monetary Economics, 50(3), April 2003, 581-604.

[22] Hansen, L. P. and T. J. Sargent, Robust Control and Economic Model Uncertainty, Princeton University Press, 2004.

[23] Ireland, P. N., "Money's Role in the Monetary Business Cycle," NBER Working Paper No. 8115, Feb. 2001c.

[24] Issing, O., "Monetary Policy in a Changing Economic Environment," in Proceedings of a Conference on Rethinking Stabilization Policy, Federal Reserve Bank of Kansas City, Aug. 29-31, 2002, 183-205.

[25] Jenkins, P. and D. Longworth, "Monetary Policy and Uncertainty," Bank of Canada Review, Summer 2002, 3-10.

[26] Jensen, H., "Targeting Nominal Income Growth or Inflation?" American Economic Review, 92(4), Sept. 2002, 928-956.

[27] Levin, A. T. and J. C. Williams, "Robust Monetary Policy with Competing Reference Models," Journal of Monetary Economics, forthcoming, 2003a.

[28] Levin, A. T. and J. C. Williams, "Parameter Uncertainty and the Central Bank's Objective Function," July 2003b.

[29] Levine, P. and D. Currie, "The Design of Feedback Rules in Linear Stochastic Rational Expectations Models," Journal of Economic Dynamics and Control, 11(1), March 1987, 128.

[30] Mehra, Y. P., "Level and Growth Policy Rules and Actual Fed Policy Since 1979," Journal of Economics and Business, 54(6), Nov./Dec. 2002, 575-594. 
[31] McCallum, B. T., "Should Monetary Policy Respond Strongly to Output Gaps?" American Economic Review, 91 (2), May 2001, 258-262.

[32] McCallum, B. T. and E. Nelson, "Timeless Perspective vs. Discretionary Monetary Policy in Forward-Looking Models," NBER Working Papers No. 7915, Sept. 2000.

[33] Onatski, A., "Robust Monetary Policy under Model Uncertainty: Incorporating Rational Expectations," Columbia University (no date).

[34] Onatski, A. and J. H. Stock, "Robust Monetary Policy under Model Uncertainty in a Small Model of the U.S. Economy," Macroeconomic Dynamics 2002, 6, 85-110..

[35] Onatski, A. and N. Williams, "Modeling Model Uncertainty," Feb. 2003.

[36] Orphanides, Athanasios, "Monetary Policy Evaluation with Noisy Information," Journal of Monetary Economics, 50(3), April 2003a, 605-631.

[37] Orphanides, A., "The Quest for Prosperity without Inflation," Journal of Monetary Economics, 50(3), April 2003b, 633-663.

[38] Orphanides, A. and S. van Norden, "The Unreliability of Output Gap Estimates in Real Time," Review of Economics and Statistics, forthcoming, 2003.

[39] Orphanides, A. and J. C. Williams, "Robust Monetary Policy Rules with Unknown Natural Rates," Brookings Papers on Economic Activity, 2002: 2, pp. 63-145.

[40] Pearlman, J. G., "Reputational and Nonreputational Policies under Partial Information," Journal of Economic Dynamics and Control, 16(2), 1992, 339,-358.

[41] Peersman, G. and F. Smets, "The Taylor Rule: A Useful Monetary Policy Benchmark for the Euro Area?" International Finance 2 (1999), 85-116. 
[42] Poole, W., "Optimal Choice of Monetary Policy Instrument in a Simple Stochastic Macro Model," Quarterly Journal of Economics, 84(2), May 1970, 197-216

[43] Rabin, M., "Psychology and Economics," Journal of Economic Literature, 36(1), March 1998, 11-46.

[44] Rogoff, K., "The Optimal Commitment to an Intermediate Monetary Target," Quarterly Journal of Economics, 100(4), Nov. 1985, 1169-1189.

[45] Rotemberg, J. J. and M. Woodford, "An Optimizing-Based Econometric Model for the Evaluation of Monetary Policy," NBER Macroeconomic Annual 1997, Cambridge, MA: MIT Press, 297-346.

[46] Rudebusch, G. D., "Is the Fed Too Timid? Monetary Policy in an Uncertain World." Review of Economics and Statistics 83 (May 2001) pp. 203-217.

[47] Rudebusch, G. D., "Assessing Nominal Income Rules for Monetary Policy with Model and Data Uncertainty.” Economic Journal 112 (April 2002) pp. 402-432.

[48] Sims, C. A., "Pitfalls of a Minimax Approach to Model Uncertainty," American Economic Review Papers and Proceedings, 91(2), May 2001, 51-54,Jan. 2001

[49] Smets, F., "Output Gap Uncertainty: Does it Matter for the Taylor Rule?" in B. Hunt and A. Orr (eds.), Monetary Policy Under Uncertainty, Wellington, New Zealand: The Reserve Bank of New Zealand, 1999, 10-29.

[50] Söderström, U., "Monetary Policy with Uncertain Parameters," Scandinavian Journal of Economics 104 (1), March 2002, pp. 125-145.

[51] Stock, J. H., "Comment on 'Policy Rules for Inflation Targeting'," in J. B. Taylor, ed., Monetary Policy Rules, Chicago: University of Chicago Press, 1999, 253-259. 
[52] Svensson, L. E. O., "Optimal Inflation Contracts, 'Conservative' Central Banks, and Linear Inflation Contracts," American Economic Review, 87(1), Mar. 1997, 98-114.

[53] Svensson, L. E. O., "How Should Monetary Policy Be Conducted in an Era of Price Stability," in New Challenges for Monetary Policy, Federal Reserve Bank of Kansas City, 1999, 195-259.

[54] Svensson, L. E. O., "Robust Control Made Simple," Princeton University, Oct. 2000.

[55] Svensson, L. E. O., "What is Wrong with Taylor Rules? Using judgement in Monetary Policy through Targeting Rules," Journal of Economic Literature, June 2003, 426-477.

[56] Svensson, L. E. O. and Michael Woodford, "Indicator Variables for Optimal Monetary Policy under Asymmetric Information," Princeton University, June 2002.

[57] Svensson, L. E. O. and M. Woodford, "Indicator Variables for Optimal Policy," Journal of Monetary Economics, 50(3), April 2003a, 691-720.

[58] Svensson, L. E. O. and M. Woodford, "Implementing Optimal Policy through InflationForecast Targeting," in B. S. Bernanke and M. Woodford (ed.), Inflation Targeting, Chicago: University of Chicago Press, 2003b.

[59] Taylor, J. B., "Discretion versus Policy Rules in Practice," Carnegie-Rochester Conferences Series on Public Policy, 39, Dec. 1993, 195-214.

[60] Vestin, D., "Price-Level Targeting versus Inflation Targeting in a Forward-Looking Model," IIES, Stockholm University, May 2000.

[61] Walsh, C. E., "Optimal Contracts for Central Bankers," American Economic Review, 85(1), Mar. 1995, 150-167.

[62] Walsh, C. E., "Speed Limit Policies: The Output Gap and Optimal Monetary Policy," American Economic Review 93(1), March 2003a, 265-278. 
[63] Walsh, C. E., Monetary Theory and Policy, 2nd ed., Cambridge: MIT Press, 2003b.

[64] Weil, P., "Non-Expected Utility in Macroeconomics," Quarterly Journal of Economics, 105, 1990, 29-42.

[65] Williams, J. C., "Simple Rules for Monetary Policy," Federal Reserve Bank of San Francisco Economic Review 2003, 1-12.

[66] Woodford, M., "Optimal Policy Inertia," NBER Working Paper 7261, Aug. 1999.

[67] Woodford, M., Interest and Prices: Foundations of a Theory of Monetary Policy, unpublished, Princeton University, 2002. 
Table 1: Calibrated parameters

\begin{tabular}{cc}
\hline & Structural parameters \\
$\beta$ & 0.99 \\
$\sigma$ & 0.16 \\
& 0.024 \\
& Shock processes \\
$\sigma_{\chi}$ & 0.005 \\
$\sigma_{u}$ & 0.03 \\
$\sigma_{\varepsilon}$ & 0.015 \\
& Loss function \\
$\lambda_{x}$ & 0.048 \\
$\lambda_{i}$ & 0.077 \\
\hline
\end{tabular}

Table 2: Performance of simple rules with imperfect information

\begin{tabular}{|c|c|c|c|}
\hline \multicolumn{4}{|c|}{ Loss as percent of full information commitment } \\
\hline & Commitment & $\mathrm{TR}$ & DR \\
\hline \multicolumn{4}{|c|}{$\rho_{y^{n}}=0, \rho_{e}=0$} \\
\hline$L$ & 100 & 107 & 101 \\
\hline$H$ & 102 & 109 & 103 \\
\hline \multicolumn{4}{|c|}{$\rho_{y^{n}}=0.9, \rho_{e}=0$} \\
\hline$L$ & 100 & 107 & 101 \\
\hline$H$ & 104 & 111 & 105 \\
\hline \multicolumn{4}{|c|}{$\rho_{y^{n}}=0.9, \rho_{e}=0.35$} \\
\hline$L$ & 100 & 117 & 101 \\
\hline$H$ & 101 & 120 & 104 \\
\hline
\end{tabular}




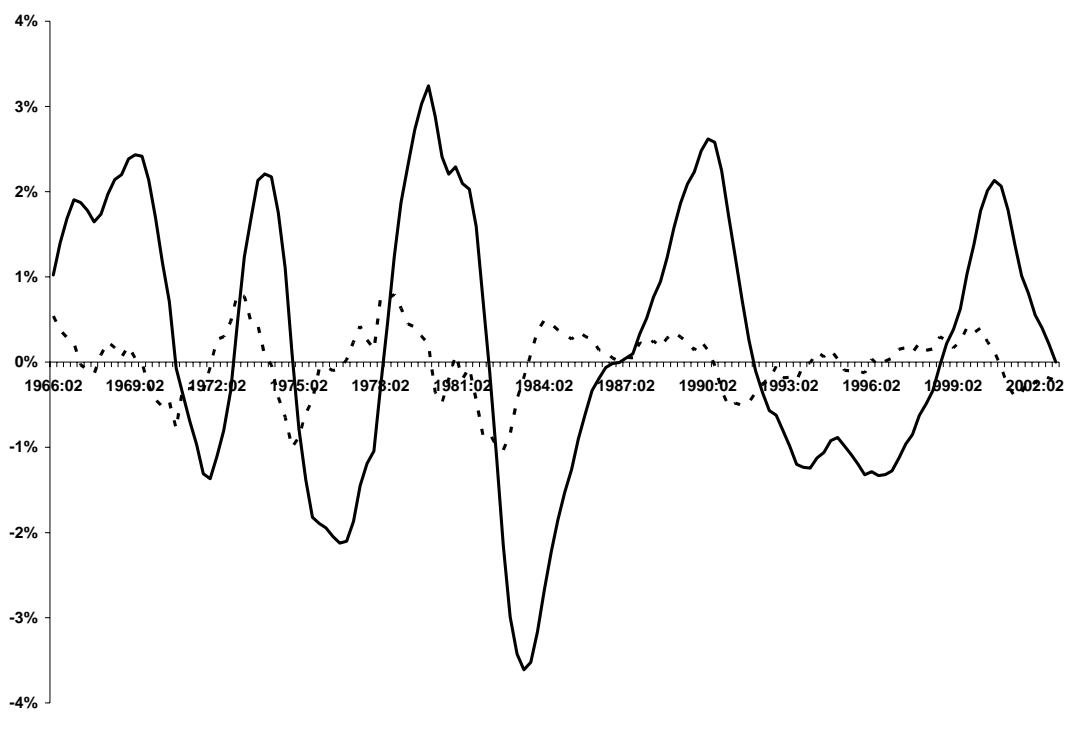

Figure 1: Revisions to the estimated output gap level and change

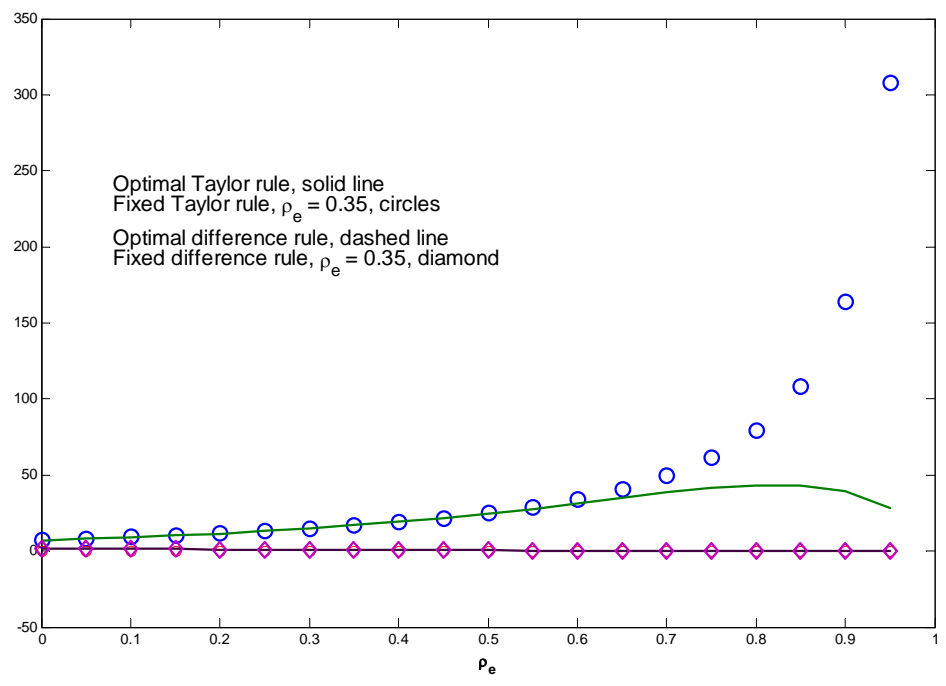

Figure 2: Increase in loss relative relative to ROE rule as a function of serial correlation in the cost shock 


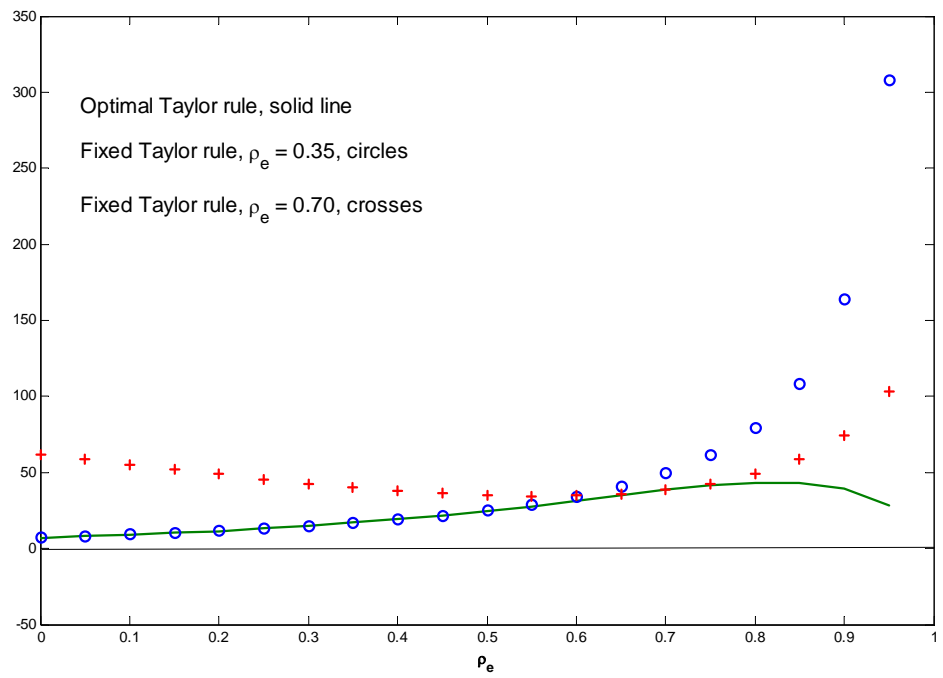

Figure 3: Increase in loss relative relative to ROE rule for an optimal Taylor rule and Taylor rules optimized for fixed values of $\rho_{e}$.

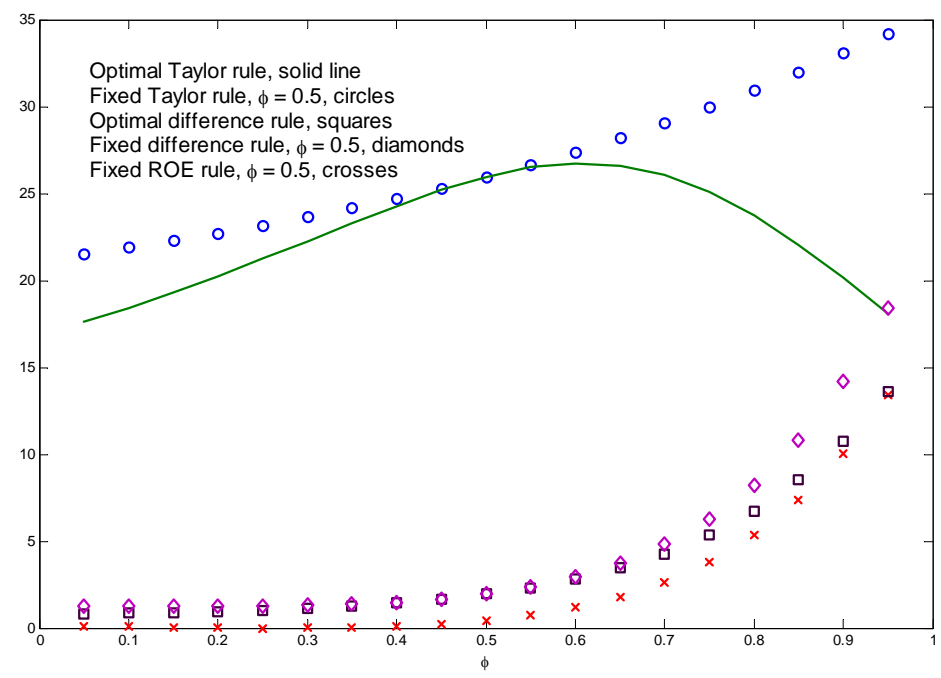

Figure 4: Increase in loss relative relative to ROE rule as a function of inflation inertia 


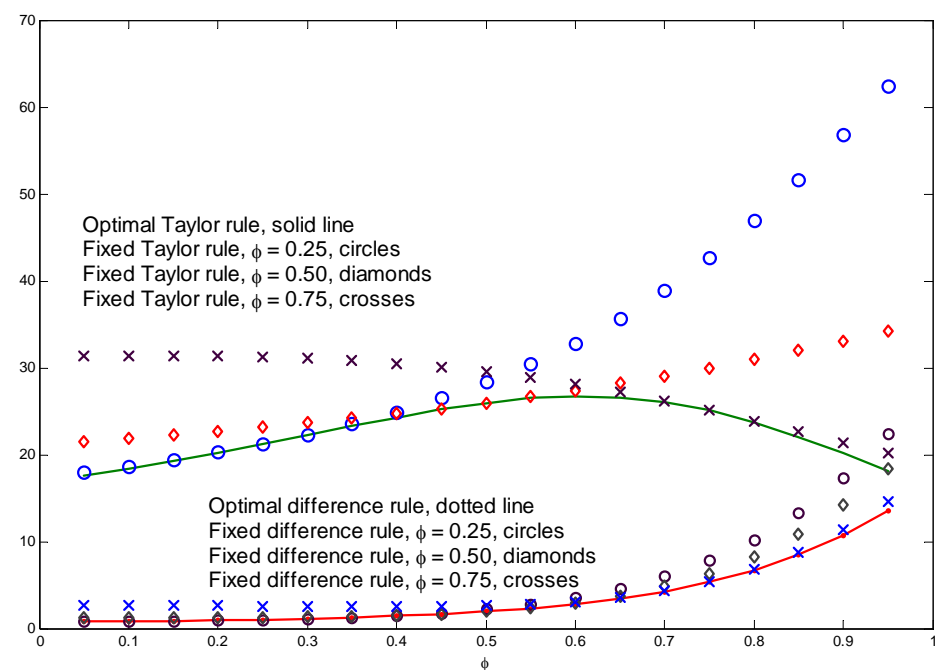

Figure 5: Increase in loss relative relative to ROE rule as a function of $\phi$

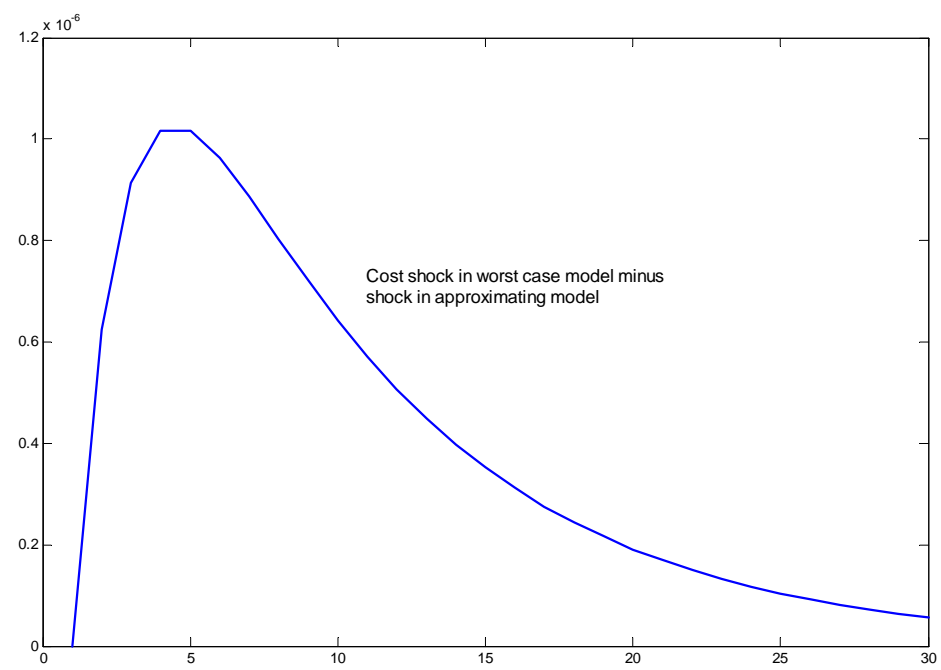

Figure 6: Difference between costs shocks in worst-case model and approximating model 


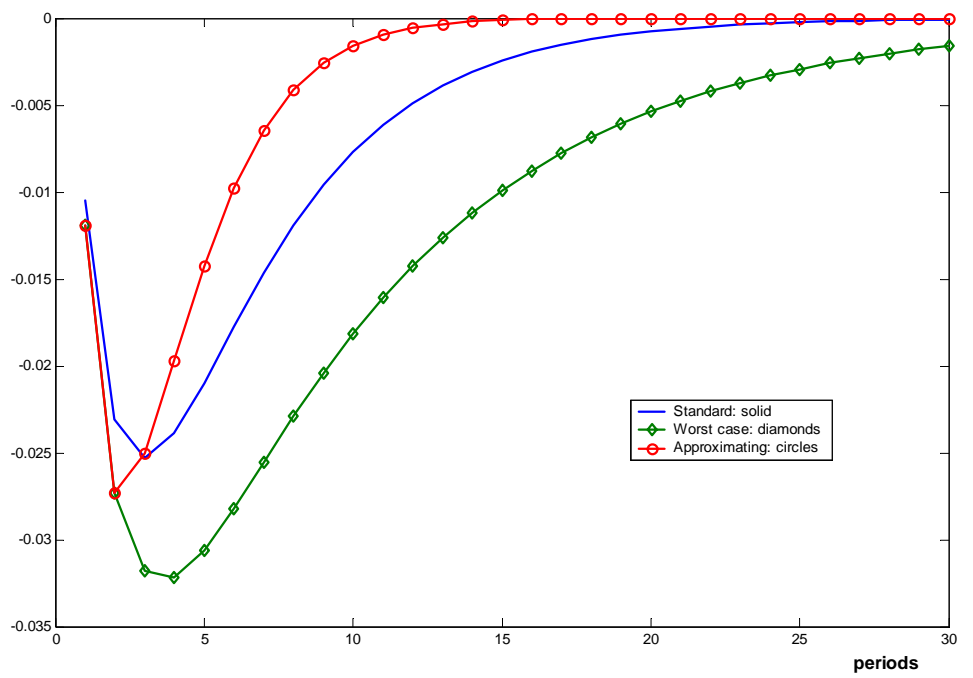

Figure 7: Output gap response to a cost shock under standard and robust policies in worst-case and approximating models 